\title{
CORPORATE AND NON-PROFIT SOCIAL MEDIA POLICIES: A CONTENT ANALYSIS
}

\section{ANALIZA SADRŽAJA POLITIKA ZA KORIŠTENJE DRUŠTVENIH MEDIJA PODUZEĆA I NEPROFITNIH ORGANIZACIJA}

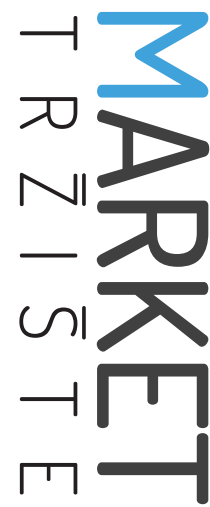

\author{
Market-Tržište \\ Vol. 29, No. 1, 2017, pp. 7-22 \\ UDK 004.738.4:65.017.1:334.012.46 \\ D0l http://dx.doi.org/10.22598/mt/2017.29.1.7 \\ Preliminary communication
}

\section{Morana Fudurića, Andreina Mandellib \\ a) Faculty of Economics and Business, University of Zagreb, Trg J. F. Kennedyja 6, 10000 Zagreb, CROATIA, mfuduric@efzg.hr \\ b) Bocconi School of Management, Via Bocconi, 8, 20136 Milan, ITALY, andreina.mandelli@sdabocconi.it}

\section{Abstract}

Purpose - The purpose of this paper is to explore the characteristics of corporate and non-profit social media policies (SMP).

Design/Methodology/Approach - Content analysis was used to empirically examine corporate and non-profit social media policies that are publically available online.

Findings and implications - The results indicate the majority of policies receiving average scores. Additionally, the research has shown no statistically significant differences between profit and non-profit policies. The research provides a framework for analyzing organizational SMPs to reveal gaps and identify areas for improvement.

Limitations - Only SMPs that are publically available online were used in content analysis. Also, the interpretation of the elements of competing values framework (CVF) used in the analysis might lead to subjective results.

Originality - To the best of our knowledge, this is one of the few papers to examine and compare corporate and non-profit SMPs.

Keywords - social media policies, CVF, non-profit organizations, corporations

\section{Sažetak}

Svrha - Svrha je ovog rada istražiti karakteristike politika za korištenje društvenih medija poduzeća i neprofitnih organizacija.

Metodološki pristup - Korištena je metoda analize sadržaja kako bi se analizirale politike za korištenje društvenih medija poduzeća i neprofitnih organizacija javno dostupnih na internetu.

Rezultati i implikacije - Rezultati pokazuju da je većina politika prosječna, što upućuje da analizirane politike ne daju dovoljno informacija, uputa, ne motiviraju zaposlenike/volontere i ne potiču konkretne akcije. lako su utvrđene određene razlike između karakteristika politika profitnih i neprofitnih organizacija, one nisu bile statistički značajne. Istraživanje se može koristiti kao podloga za analizu politika za korištenje društvenih medija te identifikaciju njihovih prednosti i nedostataka.

Ograničenja - $U$ analizi su korištene samo one politike koje su bile javno dostupne putem interneta. Isto tako elementi CVF okvira mogu biti podložni interpretaciji i subjektivnosti istraživača, što može utjecati na rezultate.

Doprinos - Prema saznanjima autora, ovo je jedan od rijetkih radova koji empirijski istražuje politike za korištenje društvenih medija profitnih i neprofitnih organizacija.

Ključne riječi - politike korištenja društvenih medija, CVF, neprofitne organizacije, korporacije 


\section{INTRODUCTION}

Since its emergence, social media has attracted millions of users worldwide. This, in turn, has made social media platforms interesting to various types of organizations seeking new ways to connect and interact with their current and potential consumers and other stakeholders. As decision makers, marketers, and consultants try to identify ways in which organizations can make profitable use of social media platforms, such as YouTube, Facebook, and Twitter, they are also faced with a decision: should all employees or volunteers be encouraged and permitted to participate in social media as spokespeople for the organization? This question should be taken seriously as employees and volunteers are often considered to be the most valuable assets in social media strategies (see Bernoff \& Schadler, 2010). The "all or expert only communicators" issue has recently been highlighted in scholarly journals. For example, O'Connor and others (2016) suggest that "while social media can have significant benefits for organizations, the social media presences and postings of employees can be problematic for organizations" (p. 205). To tackle this issue, organizations began developing social media policies in order to effectively and consistently support branding efforts and communicate their values (see also Vaast \& Kaganer, 2013). However, merely having a social media policy is not enough. O'Connor and others (2016) suggested that social media policies need to be well drafted, clear, and clearly communicated so employees understand the policy.

The main purpose of this paper is twofold. First, the paper aims to examine corporate and non-profit social media policies in order to determine their main characteristics. Second, findings are contrasted with respect to profit vs. non-profit organizations to examine if there are any patterns that emerge. In that sense, our paper builds and expands on the research of Fuduric and Mandelli (2014) and Vaast and Kaganer (2013). Contrary to the approach of Vaast and Kaganer (2013), who explore how social media policies reflect affordances as action potentials of social media in organizations, the main focus is on understanding how social media policies are being communicated to employees and/or volunteers.

The paper is organized as follows. First, a theoretical framework for the work is presented, followed by an outline of corporate and non-profit use of social media. The benefits and importance of organizational policies are discussed. Second, research methodology, namely key research questions, method and unit of analysis, and a description of the coding procedure is presented. Third, the main findings are presented based on research questions of interest, together with a detailed discussion in relation to the existing literature and expected outcomes. The final section of the paper summarizes the main conclusions, and presents limitations of the research, implications, and future research directions.

\section{LITERATURE REVIEW}

\subsection{Social media}

Kaplan and Haenlein (2010) argued that "the current trend toward social media can therefore be seen as an evolution back to the Internet's roots, since it retransforms the World Wide Web to what it was initially created for: a platform to facilitate information exchange between users" (p. 60). In that context, we can consider bulletin boards (BBS), forums and chat rooms as the earliest forms of social media. The first social network sites appeared in the late 1990s (e.g. Six Degrees) but have experienced rapid growth and popularity during the 2000s with the emergence of social networks, such as Linkedln and MySpace in 2003, Facebook in 2004, and Twitter in 2006 (Boyd \& Ellison, 2007). This does not imply social media is merely a "revival" of the Internet as it once was. Social media has only further emphasized the "digital revolution" that began with the rapid technological and communication changes brought forth by the Internet, and has used these technological advances to 
empower the consumer, facilitate online interactions and sharing which is "fundamentally different from, and more powerful than, the BBS of the late 1970s" (Kaplan \& Haenlein, 2010, p. 60).

Conceptually, social media draws on the fundamental concepts of the Web 2.0 and UGC. The Web 2.0 has often been described as "facilitating dialogue and participation" and is often discussed in the context of various forms and platforms (Campbell, Pitt, Parent \& Berthon, 2011; Deighton \& Kornfeld, 2009). It is precisely the emergence of Web 2.0 technologies that has enabled the rapid growth and popularity of social media. On the other hand, the term user-generated content is used in the context of consumer behavior. More specifically, it reflects how consumers use the technologies and platforms available as content creators. As such, social media dominantly reflects the social component and content creation, consumption and distribution (Berthon, Pitt, Plangger \& Shapiro, 2012). Therefore, it is no surprise that the majority of social media definitions link social media to Web 2.0 as its technological foundation, and stress its main feature - the facilitation of interactions and collaboration. For example, Kaplan and Haenlein (2010) define social media as "...a group of Internet-based applications that build on the ideological and technological foundations of Web 2.0 and that allow the creation and exchange of User Generated Content" (p. 61). In a similar vein, social media has been defined from a communication perspective. For example, Howard and Parks (2012, p. 359) define social media as "consisting of the information infrastructure and tools used to produce and distribute content that has individual value but reflects shared values; the content that takes the digital form of personal messages, news, ideas, that become cultural products; and the people, organizations and industries that produce and consume both the tools and the content."

Hennig-Thurau, Hofacker and Bloching (2013) argue that social media has had such a profound impact on marketing and business as a whole, that marketing scholars have yet to explore and understand. A good comparison between the "old" and "new" marketing is depicted by a bowling vs. pinball metaphor presented by Hennig-Thurau and others (2010), in which the "old" marketing resembles bowling, where the company uses traditional instruments (i.e. the bowling ball) to influence their consumers. The "new" marketing in a social media environment, however, resembles a somewhat chaotic game of pinball where the balls bounce back in different directions based of consumer interactions and feedback (Hennig-Thurau et al., 2010). This example clearly shows that an organization's social media participation is a complex game that requires a different approach. As Berthon and others (2012) pointed out, with the emergence and increasing use of social media by both consumers and organizations, marketing had to transform from the more "traditional" unidirectional, broadcasting-based marketing to an approach based on interactivity, personalization, real-time, and collaboration with a community of users.

\subsection{Corporate vs. non-profit use of social media}

The level of professionalization and development of social media policies and guidelines will depend on the organizations' type, culture, values, strategy, and use of social media. In this paper, the focus is on how social media policies differ depending on organizational type and social media use. Regarding organizational type, one of the most important differences between corporations and non-profit organizations is their core purpose, nature of the target audience, benefits offered to such audiences, and the behaviors both types of organizations tend to (try to) influence (Andreasen \& Kotler, 2008). More specifically, Gallagher and Weinberg (1991) argue that "non-profits have multiple, nonfinancial objectives; cater to multiple publics, including customers who often are not the ones who pay; they can collaborate as well as compete with competitors; and they garner more public attention, both positive and negative, than the average business" (p. 27). While the ultimate objective of corporations is sales and profit, for

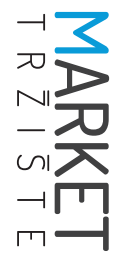




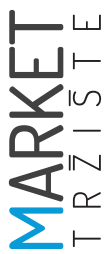

non-profit organizations it is behavioral change. In other words, non-profit organizations' core offering is often quite intangible in nature, as non-profits mostly offer services and ideas that aim to transform the society. Andreasen (2012) notes that non-profit organizations: (1) support and promote certain behaviors (e.g. eating less, exercising more); (2) aim at hindering certain harmful behaviors (e.g. eating fattening foods, using illegal drugs, paying for illicit sex) or continue inaction (e.g. not smoking), and (3) propose behaviors that mostly impose costs on target audiences (expenses and annoyance) for benefits that are mainly for third parties or the society (e.g., recycling programs).

In order to meet their objectives, non-profit organizations rely heavily on developing relationships with their multiple audiences and communication. While corporations are more concerned with traditional, strategic communication (i.e. risk-avoiding behavior), non-profit organizations are more focused on communication that is: (1) open, candid, and aims at establishing trust and development of longterm relationships with target audiences and (2) transformational and aims to stimulate behavioral change in the society.

Over the years, a growing body of literature has explored different ways organizations use social media. What initially started as a social interaction and communication tool now spans across all areas of business. For example, researchers suggest marketers can utilize social media as part of the process of value co-creation (Gebauer, Füller \& Pezzei, 2013), to foster dialogue (Saxton \& Waters, 2014), spur innovation (Füller, Jawecki \& Mühlbacher, 2007), and develop longterm profitable relationships (Himelboim, Golan, Moon \& Suto, 2014; Parasnis, 2011). Moreover, the extensive corporate use of social media has led to the emergence of enterprise social media and the social business where social media is not only used for external communication, but also for internal communication and is embedded in all aspects of the business (Leonardi, Huysman \& Steinfield, 2013).
Macnamara and Zerfass (2012) argue that social media has enabled the transformation of society by enabling the citizens to express their opinions and freely discuss matters of general interest. Social transformation is precisely the core purpose of non-profit organizations (Andreasen, 2012), so it is logical to assume non-profit organizations will use social media to meet their objectives. Non-profits can use social media to streamline their management functions, interact with stakeholders, and educate others about their programs and services (Waters, Burnett, Lamm \& Lucas, 2009; Cho, Schweickart \& Haase, 2014; Auger, 2013). These benefits are particularly interesting if we consider the budget constraints many non-profits are often faced with (Curtis et al., 2010). Additionally, social media can help non-profits develop stronger, deeper relationships with their stakeholders, as well as in organizing around different causes through mutual collaborations (Briones, Kuch, Liu \& Jin, 2011). Finally, recent research on the non-profit use of social media has focused on how social media has changed non-profit advocacy. For example, Guo and Saxton (2014) examined the types of social media technologies employed, while also conducting an in-depth message level examination of the organizations' use of Twitter for advocacy purposes.

While many corporations have been at the forefront of social media adoption and use, non-profit organizations seem to fall behind in the usage of various social media platforms to meet their objectives. For example, Waters and others (2009) have found that many non-profits fail to utilize the interactive function of social media. It has been argued that non-profits dominantly use social media to "relay information using one-way communication" (Lovejoy, Waters \& Saxton, 2012, p. 316; Auger, 2013). Lovejoy and Saxton (2012) reported similar results in their analysis of non-profit organizations' social media utilization, classified in three broad categories based on their primary function: information sharing, community building, or action seeking; they found information sharing to be 
still the dominant primary function of social media for non-profit organizations.

Regardless of the type of organization, we can say that almost all organizations follow a certain social media adoption process. For example, Mergel and Bretschneider (2013) directly link the social media adoption process to the development and implementation of social media policies. The authors suggest that the organizational diffusion of social media applications and other new technologies follows a three-stage process. First, organizations experiment informally with social media outside of accepted technology use policies. Next, order evolves from the first chaotic stage as organizations recognize the need to draft norms and regulations. Finally, organizations evolve and clearly outline appropriate behavior, types of interactions, and new modes of communication that are subsequently formalized in social media strategies and policies, which we address in detail in the next section.

\subsection{Organizational social media policies}

Almost all organizational decision-making is guided by policies (Nabukenya, Van Bommel, Proper \& De Vreede, 2011). In general, such policies can be defined as "instances of organizational directives (as in instructions, prescriptions, proscriptions) pertaining to particular realms of human behavior, the ensuring variations are almost as limitless as the realms of group life to which matters of policy or organizational directives are pertinent" (Prus, 2003, p. 16). In other words, organizational policies refer to all documents that outline the guiding principles related to a specific topic (e.g. privacy policy or IT use) that are designed by senior management to shape employees' actions, behaviors, and perceptions (Six \& Sorge, 2008; Vaast \& Kaganer, 2013). Because organizational policies can be viewed as elements of the work environment that impact workers' daily activities and behaviors, they draw significantly on corporate values and corporate culture (Foote, Seipel, Johnson \&
Duffy, 2005). As a result, if a corporation or organization places high value on, for instance, high productivity, privacy or gender equality, it is highly likely the organization will develop, implement, and stress the importance of such policies to employees. Since the policy's main objective is to guide and/or regulate employee behavior, it has been argued that such rule following is critical for organizations in order to function effectively and is often portrayed as critical for successful functioning (Tyler \& Blader, 2005).

Because organizations implement a wide variety of organizational policies to govern their internal and external business activities, research on organizational policies is quite fragmented. As a result, research on organizational policies has its roots in a number of diverse disciplines, such as management, sociology, psychology, communication, and ethics, with many papers taking on an interdisciplinary approach to the study of organizational policies. For example, a significant body of research has developed around how organizational policies may drive employee commitment and the development of a deep understanding of antecedents of "rule following" in work settings (see, for example, Foote at al., 2005; Tyler \& Blader, 2005); the organizational policy development as a collaborative process (see, for example, Nabukenya et al., 2011; Prus, 2003) and finally, ethical and legal issues pertaining to organizational policies (see, for example, Epstein, 1987; Gruber, 1998; King \& Cortina, 2010).

Organizational policies are essential especially when it comes to IT governance because not only do they play an important role in shaping employees' perceptions and expectations, but also help in developing a shared understanding of its possibilities, pros, and cons (Huang, Zmud \& Price, 2010; Vaast \& Kaganer, 2013). Kaganer and Vaast (2010) point to the fact that the formulation of policies is "one of the most prevalent tools employed by managers to communicate the formal position of an organization on a variety of matters, including [its] use of IT innovations and traditional media" (p. 4).

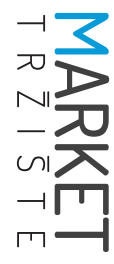




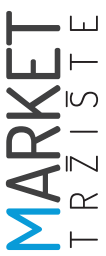

In the context of social media, one critical matter is whether all employees or volunteers should be permitted to participate in the interactions as representatives of the organization. On the one hand, social media call for a different, interactive, open, and personalized approach to communication, which implies the involvement of all employees and/or volunteers of the organization (see also Kaplan \& Haenlein, 2010). On the other hand, such an open approach to communication is in contrast with corporate communication theories, that suggest corporate communication should be left to communication experts, and fully aligned with organizational strategy and management processes (Macnamara \& Zerfass, 2012). As a result, organizations began developing social media policies in order to: (1) clearly state their views on the importance and role of social media for the organization; (2) manage employee expectations regarding the organization's social media presence, and (3) effectively and consistently support communication and branding efforts and communicate the organization's values (see also Vaast \& Kaganer, 2013.). In this context, and for the purpose of our research, social media policies can be defined as "a set of instructions, policies, and recommended practices set forth by the organization in order to guide the employee's personal and professional presence in various social media platforms".

While other types of organizational policies have been widely studied, there is limited research available regarding social media policies (Kaganer \& Vaast, 2010). For example, Vaast and Kaganer (2013) explore how social media policies reflect affordances (i.e. visibility, persistence, editability, and association) as aspects of action potential of social media in organizations. By conducting a content analysis on a sample of social media policies, the authors found that organizations especially reacted to the affordances of visibility and persistence rather than editability. The results also indicate that organizations' reactions to social media tend to evolve from being focused on risk-management to considering the value-generating potential of social media. On the other hand, Fuduric and Mandelli (2014) explored how social media guidelines are being communicated to employees by using content analysis of selected social media guidelines based on the Competing Values Framework (i.e. to which degree each guideline can be characterized as informative, instructional, transformational, or relational). However, researchers did not compare features of social media policies of different types of organizations (e.g. profit vs. non-profit vs. public), even though it has been shown in earlier sections of this paper that such organizations may differ in their use and level of adoption of social media.

\section{METHODOLOGY}

In this section, we will present the main research questions guiding this study, as well as the method and unit of analysis, sampling method, and coding procedure.

\subsection{Research questions guiding the study}

The exploration of social media guidelines and policies has received some attention in recent years (see, for example, Fuduric \& Mandelli, 2014; Vaast \& Kaganer, 2013). Contrary to the approach of Vaast and Kaganer (2013), who adopt the affordances approach, our main focus is on understanding how social media policies are being communicated to employees and/or volunteers. More specifically, we are interested in the degree of information, instruction, structure, and incentive social media policies provide to employees and/or volunteers. As a reminder, policies are used to communicate the organization's official stance with regard to a focal phenomenon (i.e. social media) and they aim at conditioning end users' (i.e. employees' and volunteers') practices (see also Castro \& Batel, 2008). Moreover, Prus (2003) stresses that, while there is no official requirement for policies to be particularly articulated (e.g. clear, precise, thorough, or systematic), carefully and thoroughly 
articulated policies contribute to a sense of its authenticity and realism in the organization, and may improve its comprehensiveness and implementation. This is consistent with the views and approach of Fuduric and Mandelli (2014), who adopt the communication approach in their assessment of social media policies; therefore, we build and expand on that research by examining and comparing corporate and non-profit social media policies. More specifically, the study aims at answering the following questions:

\section{RQ 1. Which transformational, instruc- tional, informational, and relational aspects can be found in social media policies?}

This research question pertains to the content of social media policies. As noted earlier, it is important not only to have a social media policy in place, but also how the policy is being formulated and communicated to employees and/ or volunteers. Among other things, social media policies should be well-drafted, clear, and avoid any type of ambiguity (O'Connor, Schmidt \& Drouin, 2016). In the context of different aspects of social media policies, a good balance between transformational, instructional, informational, and relational aspects is advised (Quinn, Hildebrandt, Rogers \& Thompson, 1991).

\section{RQ 2. Are there any significant differences between profit and non-profit social media policies, and how can these be explained?}

Non-profit organizations' core purpose is social transformation (Andreasen, 2012), and social media enable them to meet that objective (Macnamara \& Zerfass, 2012). Due to their nature, non-profit organizations can be expected to exhibit a propensity towards relational and transformational approaches in their social media policies. On the other hand, because non-profits have been proven to fall behind in their social media adoption and use (Waters et al., 2009; Lovejoy \& Saxton, 2012), their social media policies can also be expected to be not as well presented as corporate ones.

\subsection{Method of analysis}

Content analysis was used to examine the organizations' social media policies based on the adapted Competing Values Framework (CVF). Content analysis was chosen as the method of analysis for the following reasons: First, content analysis is a "...research technique for making replicable and valid inferences from texts (or other meaningful matter) to the contexts of their use" (Krippendorff, 2004, p. 18). Since social media policies are written (text) documents, content analysis was considered suitable for this study. Second, content analysis was a method of choice in previous studies that examined various types of organizational policies (e.g. Vaast \& Kaganer, 2013). Finally, Krippendorff (2004) argued that content analysis can be used to determine what is being communicated and how. Taking into account the research questions of this study, content analysis was considered as a suitable method.

CVF was originally created and widely used in the management literature to evaluate organizational culture and effectiveness (Quinn et al., 1991). It was described as a "a set of systematic steps, and a methodology for helping managers and their organizations carefully analyze and alter their fundamental culture" (Cameron \& Quinn, 2005, p. 65). Since then, it has been used to assess business and ethical codes, as well as other types of business documents, such as business and sales presentations, privacy policies etc. (e.g. Quinn et al., 1991; Stevens, 1994, 1996), and was therefore considered suitable for this study. The framework consists of four quadrants (i.e. transformational, instructional, informational, and relational) that are defined based on 12 descriptors (see Figure 1).

Each document can be examined by scoring it on each of the twelve descriptors using a 7-point scale to reveal its strengths and weaknesses depending on the obtained score. For example, if a document scores low for being "practical, informative, realistic", it suggests that the analyzed document does not provide the 
FIGURE 1: Competing Values Framework

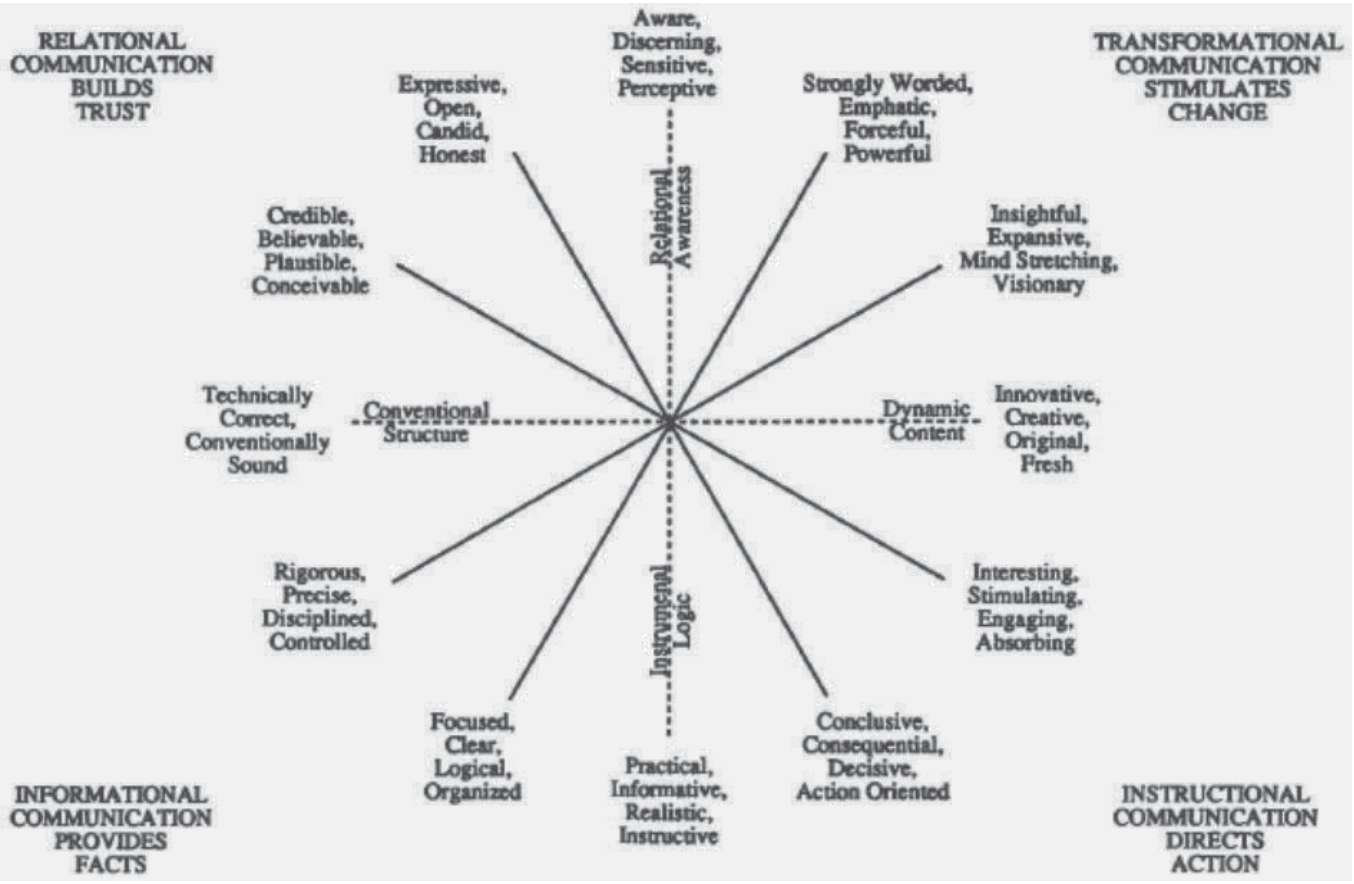

Source: Quinn et al. (1991)

employees with enough information on a given topic and is unable to resolve possible dilemmas by providing relevant facts and details (Stevens, 1996). This goes to show that the CVF can be used to reveal the gaps in each document, and point to opportunities for its improvement.

\subsection{Unit of analysis and sampling method}

The unit of analysis is social media policies of various companies and non-profit organizations. The criterion for the selection of organizational policies was twofold: first, organizations of interest were identified based on Fortune's 500 list of companies. Second, a Google search was conducted using a predefined set of keywords to identify the companies that published their social media policies online, and which of those were made publically available. A similar approach, based on the list published by The Non-profit Times, was used to identify non-profit social media policies to be examined in this study. This search resulted in 25 corporate and 25 non-profit policies that entered further analysis.

\subsection{Coding procedure}

Each identified guideline was examined by two coders and rated on a 7-point scale for twelve descriptors, adopted from the CVF framework. Additionally, the coders kept notes and comments for each guideline that facilitated further analysis. The issue of interpretability of the descriptors in CVF, more specifically, the issue of differences in individual interpretations of the descriptors and their rating on a 7-point scale, which can be highly subjective, was resolved by training the coders. The coders were first introduced to the concept of the CVF, its significance and structure, followed by three two-hour sessions of more intensive trainings during which the coders were given a comprehensive list of 
all features (descriptors), their respective definitions and examples in order to bring subjective interpretations to a minimum. Finally, the raters practiced the rating process on a separate set of policies that had not been included in the research sample. The results were tabulated by averaging the coding for each of the twelve descriptors for a given guideline. The next step included calculating the means for each of the four quadrants. The quadrant scores could range from four (low) to twenty-eight (high). More specifically, if a guideline received a score of twenty-eight, it meant that both coders assigned the highest possible score of seven to the policies, across all four sets of descriptors. Similarly, if a guideline received the minimum score of four, it means both coders assigned to the guideline a score of 1 , across all four sets of descriptors. Upon completion of the coding process, the data was analyzed using SPSS and MS Office Excel.

\section{FINDINGS AND DISCUSSION}

The analysis of inter-coder reliability resulted in an acceptable inter-coder agreement rate of $79 \%$. Additionally, an independent samples t-test confirmed there are no statistically significant differences between coders' guideline scores.

\subsection{Transformational, instructional, informational and relational aspects}

To answer the first research question, guideline scores are examined by quadrant. Overall, the results show higher scores for informative (22.41) and relational quadrants (22.47) than for transformational (17.78) and instructional (18.62) ones. Quadrant scores ranged from 14 to 27 for the informative, 15.2 to 28 for the relational, 8 to 26 for the transformational and 10.5 to 27 for the instructional quadrant. This means that the majority of policies exhibits a strong "conventional structure" dimension within the CVF, as they typically provide clear and well-structured information, and seem very credible.

With respect to the transformational quadrant, 17 out of 50 policies received a high score (20 or higher), while 4 out of 50 received a fairly low score (12 or less). Still, the majority of policies (29) ranged in the middle, which leads to the conclusion they cannot be qualified as particularly insightful, powerful, mind-stretching, or visionary. Quite the contrary, the majority of the policies has proven to be average in their transformational dimensions, with only two policies standing out in this quadrant with scores of 25 and 26. It is interesting to note here that these policies were developed by two corporations - Microsoft, from the IT sector, and P\&G as a representative of the FMCG sector - that have often been considered as the pioneers when it comes to social media use.

Similarly, scores for the instructional quadrant are also grouped together, as expected given the fact that the two quadrants share a CVF dimension labeled "dynamic content"(see Figure 1 for an outline of quadrants and dimensions). A high score (20 or higher) was assigned to 21 policies, whereas only 3 policies received a score of 12 or less for the instructional quadrant. Overall, the analyzed policies partially reflect the instructional dimension, which implies that their capacity to convey facts, detail, and direction is average. Even though the guideline scores are generally higher for the instructional quadrant, the majority of the policies (26) still cannot be characterized as particularly interesting, stimulating, engaging, action oriented, or practical. This finding reflects a lack of incentive, much needed in case an organization wishes to provide not only guidance, but also motivate the employees or volunteers to contribute to its social media platforms. For example, fewer policies contain a direct call to action or any sort of motivation for employees to actively participate in social media. Also, only a smaller number of policies contained a "best practices" section that could raise interest and provide practical examples of desired actions and behaviors. Still,

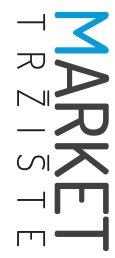


three policies scored exceptionally high with scores of $25,25.5$, and 27.

As mentioned earlier, overall the policies' scores were higher for the informative and relational quadrants that share the "conventional structure" dimension. In the informative quadrant, none of the policies received a score lower than 12 , and only 3 had a score of 14 and 15, while 40 out of 50 policies received scores of 20 or higher. This means that the policies succeeded in conveying information and facts in a clear and well-structured way that does not cause any doubt or confusion. Additionally, many policies received a fairly high score when it comes to being rigorous and precise, which is consistent with previous research of Fuduric and Mandelli (2014). This also signals an organizational concern for issues such as customer privacy, data protection, and an overall concern of organizations to follow legal and ethical frameworks (e.g. protect the privacy of employees, volunteers, and customers/users; being clear and transparent, avoid harmful, hurtful, or irrespective language, etc.).

Finally, the relational quadrant scores were exceptionally high for the majority of the policies to the organization, which closely relates to the research and findings of Vaast \& Kaganer (2013).

In terms of competing values, a tension exists between the opposite "transformational" and "informational" quadrants, as well as between the "instructional" and the "relational" quadrant. As previously suggested in the literature (Quinn et al. 1991; Stevens, 1996), although these quadrants are considered opposites in terms of their main characteristics, this does not imply that a certain dimension should be dominant. Quite the contrary - a well-balanced and effective social media guideline should score high in most (if not all) quadrants. However, the research suggests that one dimension is often traded for another. More specifically, in this case, strong scores in the informational quadrant are often contrasted with relatively low scores in the transformational quadrant.

Overall, the policies are clearly stronger in relational and informational dimensions than in transformational or instructional ones. That is, the policies communicate facts clearly, consistently, and in trust-building ways, while exhibiting fewer change-oriented and transformational characteristics.

TABLE 1: Overall, corporate and non-profit policies grand mean scores by quadrant

\begin{tabular}{|l|c|c|c|c|}
\hline & Transformational & Instructional & Informative & Relational \\
\hline GRAND MEAN (overall) & 17.78 & 18.62 & 22.41 & 22.47 \\
\hline GRAND MEAN (corporate) & 17.38 & 19.62 & 22.62 & 22.52 \\
\hline GRAND MEAN (non-profit) & 18.18 & 17.62 & 22.2 & 22.42 \\
\hline
\end{tabular}

(44 out of 50 scored over 20; only 6 received scores between 15.5 and 19.5). This means that the policies communicated the content in an open, expressive, and conventionally sound way that aims at building trust. This feature is important as it tends to establish a certain level of credibility and awareness of a topic at hand in this case - social media. Additionally, the policies conveyed a high degree of awareness of the benefits and affordances social media bring
In order to fully explore these interactions, scores of selected policies are presented within the CVF (see Figure 2). These policies have been chosen because they have overall high scores across all four quadrants, overall low scores across all quadrants or because they clearly represent the transformational-informational and relational-instructional interaction. 
FIGURE 2: Selected policies' scores by quadrant

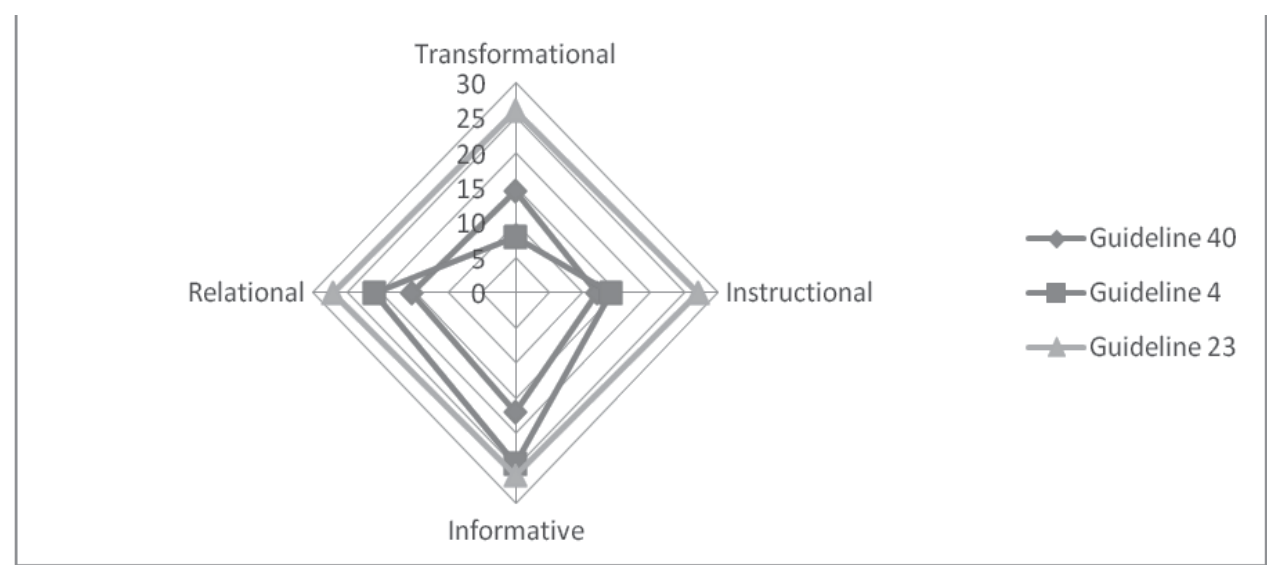

Guideline 23 ( $P \& G$ ) received high scores in all four quadrants. Moreover, it had the highest score overall in the transformational and instructional quadrant, and high scores in the relational and informational quadrant. Rater comments were reviewed to provide additional clarity. The guideline featured a short introduction in which it acknowledges the importance of new technologies and social media, and its impact on businesses. It continues by listing some of the main benefits of social media use, and links it back to the core values and principles of the company. The policy itself is very well-structured and divided into three main areas: (1) social media use as part of job responsibility, (2) social media use for collaboration and productivity, and (3) employee personal use of social media. Before providing instructions for each section, there is a detailed description of company intent, a list of stakeholders the policy applies to, and definitions of key words and phrases used within the policy. In addition, each section features links to best practices and additional material (e.g. forms, tools, platforms) that can help guide employee participation in social media, both internally and externally. Because the guideline is very well-structured, and provides not only detailed information and facts but also clear instructions and links to good practices, the guideline scored high in the informational and instructional quadrants. Thanks to the use of positive language and a clearly stated acknowledgment of the benefits social media bring to the company, the guideline also scored high in transformational and relational quadrants. For example, even though the guideline clearly lists the possible pitfalls of using social media (e.g. privacy and copyright issues, etc.), it first outlines the positive and invites and motivates the employees to participate and ask for additional advice when in need. Overall, the positive tone of the entire guideline translates as a list of useful tips and advice that aim at guiding the employees' expectations and use of different social media platforms for different purposes.

Guideline 40 (Junior Achievement, USA non-profit) received ratings below the grand mean in the transformational, instructional, informational, and relational quadrants. The policy, named "Social Media Policy for Employees and Volunteers", begin by acknowledging the importance of social media as a communication tool. However, this also signals there is a lack of full comprehension of the benefits and possible use of social media, which is one of the reasons the guideline received a low score for the transformational quadrant. Additionally, the coders described the guideline as not being particularly perceptive or visionary. In terms of other quadrants, the guideline is very poorly 


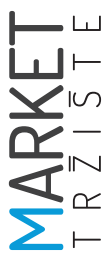

structured and does not provide information precise enough to guide employee/volunteer participation. The language is cold and impersonal, and not action-oriented. As noted by the coders, there is a general impression that the main purpose and concern of such policies is to protect the organization from any legal responsibility, as also evident in the frequent reference to legal responsibilities of the employees and their non-disclosure obligations, rather than in providing incentives and motivation to participate in social media platforms.

Guideline 4 (Baker \& Daniels) is a typical representative of the policies with an average total score, and clearly depicts the interactions between opposing quadrants (see Table 1). As shown in Figure 1, the guideline received a high score in the informational quadrant, and is described as being very precise, focused, and disciplined (e.g. clear statement of the stakeholders that should abide to the policy, followed by clear definitions of key terms). In the opposing transformational quadrant, the guideline received the lowest scores and was described as "not having any creativity or vision". This is no surprise since Baker \& Daniels is a law firm and is clearly focused on conveying facts in a clear, well-structured way, rather than stimulating change or being particularly visionary. Additionally, a similar tension exists between relational and instructional quadrants. The relatively low score in the instructional quadrant results from the fact that the guideline does not stimulate any active participation or employee engagement, nor does it provide any specific instructions on how to participate in social media platforms. Rather, it focuses on the ethical and legal framework, and what not to do or publish (e.g. "do not pat yourself on the back", "do not publish", "Do not promote successes", etc.). However, this had a bearing on the relational quadrant scores in the sense that the guideline scored higher because it seemed very credible and technically correct, and conveyed an awareness of the pitfalls of a law firms' participation in social media.

\subsection{Profit vs. non-profit social media policies}

To answer the second research question, grand means were calculated for each quadrant for profit and non-profit policies (see bottom of Table 1). Non-profit policies grand mean scores are lower in every quadrant except the transformational (17.38 for corporate vs. 18.18 for non-profit). This would imply that non-profits tend to develop policies that are characterized by transformational communication that is rich in empathy and inspiration, and aims at stimulating change; this is in line with the literature as the core purpose of non-profits, their mission, and values all aim at stimulating a positive (behavioral) change in the society. It also confirms our initial understanding and the differences that emerge between the two types of organizations based on their core purpose and activities (Andreasen, 2012), and the implications this has for SMP. However, taking into consideration that one of the main benefits of non-profit participation in social media is the development of relationships with different groups of stakeholders (Waters et al., 2009), it is surprising that non-profit policies received a slightly lower score in the relational quadrant compared to corporate policies (22.52 for corporate vs. 22.42 for non-profit). Finally, corporate SMPs scored higher in the instructional quadrant compared to non-profit ones (19.62 for corporate vs. 17.62 for non-profit). This can be linked to the differences in corporate and non-profit use of social media. For example, recent research suggests non-profit organizations still have not been able to take advantage of the benefits social media has to offer (Waters et al., 2009; Lovejoy et al., 2012; Auger, 2013). This would imply having less knowledge and experience in social media use, which can also become evident in the level of instruction (i.e. "how to" advice, specific case studies, best practices, etc.) such organizations provide within their SMPs.

To gain more insight and conclude whether these differences are statistically significant, independent samples t-test was conducted. The 
analysis revealed no statistically significant differences between profit and non-profit organizations' scores for the transformational (t (-.704; $d f=48 ; N S))$, instructional (t (1.862; $d f=48 ; N S))$, informational (t (.438; $\mathrm{df}=48$; NS), and relational ( (0.140; df=48; NS) quadrant. This result could be due to the relatively small sample size, so conducting additional research on a larger sample of social media policies is advised.

\section{CONCLUSION}

In general, there have been limited studies on social media policies and their characteristics, and no known studies that aim at contrasting these characteristics between different types of organizations. Therefore, the main purpose of the present research was to examine corporate and non-profit SMPs in order to determine their main characteristics. Second, findings were contrasted with respect to profit vs. non-profit organizations to examine if there are any patterns that emerge. Finally, a detailed examination of selected policies and their features was presented. Even though the literature suggests achieving a good balance between informational, instructional, relational and transformational characteristics of SMPs (Quinn et al., 1991; Stevens, 1996), the findings indicate organizations generally do not follow this path. For example, overall, organizational SMPs tend to focus more on informative and relational features, rather than transformational and instructional ones. Then comparing SMPs between the two types of organizations, findings indicate non-profit organizations tend to develop SMPs that are more transformational, while corporate SMPs tend to be more instructional. However, this difference was not statistically significant, so additional research is advised. Our findings have important implications for managers, as discussed next along with limitations and future research directions.

\subsection{Managerial implications}

Based on our analysis of organizational social media policies, it can be concluded that orga- nizations must not only define visionary social media policies and strategies, but also communicate them in a clear and well-structured way. This research offers several practical implications for marketers and communication experts who are developing and implementing social media strategies. First, it identifies and examines the four key dimensions of social media policies. Second, it stresses the importance of balancing out the different dimensions of the policies, rather than accepting tradeoffs. Additionally, by providing a detailed examination of three policy areas, the managers can gain additional insights into the guideline content and characteristics, and can use the framework to identify gaps, point to opportunities for improvement, or take the findings into account when developing new policies.

More specifically, this study points to several areas marketing managers need to consider when formulating and/or revising their social media policies. First, social media policies need to be well-structured, clear, and unambiguous. This means all employees should have a clear understanding of who and what the policy refers to, what is expected, and what the potential outcomes may be. It is also necessary to make a clear distinction between personal and professional employee use of social media, while keeping in mind the legal possibilities and restrictions. Additionally, the content of the policies should clearly be linked to and aligned with other relevant documents, processes, and strategies (e.g. ethical code, code of conduct, privacy policy, etc.). Second, while most organizations have policies that are rich in information, it is highly recommended to provide additional instructions, as well as links to other material, "how to" case studies, and best practices that will help guide employee participation, making them more instructional. Finally, it is important to keep in mind that social media policies are there to guide employee behavior, rather than prevent it. In other words, a well-balanced social media policy can not only provide relevant facts and direct action, it should also build trust (by

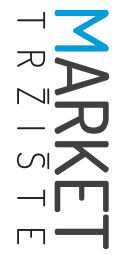


presenting content in a positive, credible, and expressive way), be motivating, and stimulate change (by presenting content that is insightful and visionary). Such a well-balanced policy can effectively communicate both the benefits and potential risks of social media by providing all the necessary facts and instructions clearly, and still keep employees motivated to participate.

\subsection{Limitations and future research directions}

A possible limitation of the research could be the issue of interpretability of the features of the framework. The quality of the research, therefore, highly depends on the quality of the training raters receive prior to the coding process. An additional limitation of the research is that the sample consisted of the policies that were made publically available online, thus resulting in a rel- atively small sample, as well as a non-significant t-test when comparing corporate and non-profit SMP. The alternative approach would be to establish a direct contact with organizations in order to obtain a larger sample of policies to be analyzed, which requires more resources.

Finally, in terms of potential new research directions, this analysis can be broadened by identifying the internal and external factors that may influence the characteristics of the policies, such as corporate culture and social business strategy. An additional possibility is to integrate this framework into more elaborate models (for example, the stages in professionalization of social media participation or the social business maturity of the organization). Finally, the research can be expanded by modeling the causality between content (competing values), process (policy publication), and outcome (degree of effectiveness).

\section{References}

1. Andreasen, A. R. (2012). Rethinking the relationship between social/non-profit marketing and commercial marketing. Journal of Public Policy \& Marketing, 31(1), 36-41.

2. Andreasen, A. R., \& Kotler, P. (2008). Strategic Marketing for Non-profit Organizations. New Jersey, NJ: Pearson Prentice Hall.

3. Auger, G. A. (2013). Fostering democracy through social media: Evaluating diametrically opposed non-profit advocacy organizations' use of Facebook, Twitter, and YouTube. Public Relations Review, 39(4), 369-376.

4. Bernoff, J., \& Schadler, T. (2010). Empowered: Unleash Your Employees, Energize Your Customers, and Transform Your Business. Boston, MA: Harvard Business Review Press.

5. Berthon, P. R., Pitt, L. F., Plangger, K., \& Shapiro, D. (2012). Marketing meets Web 2.0, social media, and creative consumers: Implications for international marketing strategy. Business Horizons, 55(3), 261-271.

6. Boyd, D. M., \& Ellison, N. B. (2007). Social Network Sites: Definition, History, and Scholarship. Journal of Computer-Mediated Communication, 13, 210-230.

7. Briones, R. L., Kuch, B., Liu, B. F., \& Jin, Y. (2011). Keeping up with the digital age: How the American Red Cross uses social media to build relationships. Public Relations Review, 37(1), 37-43.

8. Cameron, K. S., \& Quinn, R. E. (2005). Diagnosing and changing organizational culture: Based on the competing values framework. San Francisco, CA: John Wiley \& Sons.

9. Campbell, C., Pitt, L. F., Parent, M., \& Berthon, P. R. (2011). Understanding Consumer Conversations around Ads in a Web 2.0 World. Journal of Advertising, 40, 87-102.

10. Castro, P., \& Batel, S. (2008). Social representation, change and resistance: On the difficulties of generalizing new norms. Culture \& Psychology, 14(4), 475-497.

11. Cho, M., Schweickart, T., \& Haase, A. (2014). Public engagement with non-profit organizations on Facebook. Public Relations Review, 40(3), 565-567. 
12. Curtis, L., Edwards, C., Fraser, K. L., Gudelsky, S., Holmquist, J., Thornton, K., \& Sweetser, K. D. (2010). Adoption of social media for public relations by non-profit organizations. Public Relations Review, 36(1), 90-92.

13. Deighton, J., \& Kornfeld, L. (2009). Interactivity's unanticipated consequences for marketers and marketing. Journal of Interactive Marketing, 23(1), 4-10.

14. Epstein, E. M. (1987). The corporate social policy process: Beyond business ethics, corporate social responsibility, and corporate social responsiveness. California Management Review, 29(3), 99 114.

15. Foote, D. A., Seipel, S. J., Johnson, N. B., \& Duffy, M. K. (2005). Employee commitment and organizational policies. Management Decision, 43(2), 203-219.

16. Fuduric, M., \& Mandelli, A. (2014). Communicating social media policies: evaluation of current practices. Journal of Communication Management, 18(2), 158-175.

17. Füller, J., Jawecki, G., \& Mühlbacher, H. (2007). Innovation creation by online basketball communities. Journal of Business Research, 60(1), 60-71.

18. Gallagher, K., \&Weinberg, C. B. (1991). Coping with success: new challenges for nonprofit marketing. Sloan Management Review, 33(1), 27-42.

19. Gebauer, J., Füller, J., \& Pezzei, R. (2013). The dark and the bright side of co-creation: Triggers of member behavior in online innovation communities. Journal of Business Research, 66(9), 15161527.

20. Gruber, J. E. (1998). The impact of male work environments and organizational policies on women's experiences of sexual harassment. Gender \& Society, 12(3), 301-320.

21. Guo, C., \& Saxton, G. D. (2014). Tweeting social change: How social media are changing non-profit advocacy. Non-profit and Voluntary Sector Quarterly, 43(1), 57-79.

22. Hennig-Thurau, T., Hofacker, C. F., \& Bloching, B. (2013). Marketing the Pinball Way: Understanding How Social Media Change the Generation of Value for Consumers and Companies. Journal of Interactive Marketing, 27(4), 237-241.

23. Hennig-Thurau, T., Malthouse, E. C., Friege, C., Gensler, S., Lobschat, L., Rangaswamy, A., \& Skiera, B. (2010). The Impact of New Media on Customer Relationships. Journal of Service Research, 13(3), 311-330.

24. Himelboim, D. I., Golan, G. J., Moon, B. B., \& Suto, R. J. (2014). A Social Networks Approach to Public Relations on Twitter: Social Mediators and Mediated Public Relations. Journal of Public Relations Research, 26(4), 359-379.

25. Howard, P. N., \& Parks, M. R. (2012). Social Media and Political Change: Capacity, Constraint, and Consequence. Journal of Communication, 62(2), 359-362.

26. Huang, R., Zmud, R. W., \& Price, R. L. (2010). Influencing the effectiveness of IT governance practices through steering committees and communication policies. European Journal of Information Systems, 19(3), 288-302.

27. Kaganer, E., \& Vaast, E. (2010). Responding to the (almost) unknown: Social representations and corporate policies of social media. Proceedings of The $2^{\text {nd }}$ European Conference on Social Media ECSM 2015, July 9-10, 2015, Porto, 1-19.

28. Kaplan, A. M., \& Haenlein, M. (2010). Users of the world, unite! The challenges and opportunities of Social Media. Business Horizons, 53(1), 59-68.

29. King, E. B., \& Cortina, J. M. (2010). The social and economic imperative of lesbian, gay, bisexual, and transgendered supportive organizational policies. Industrial and Organizational Psychology, 3(1), 69-78.

30. Krippendorff, K. (2004). Content analysis: An introduction to its methodology. Thousand Oaks, CA: Sage. 
31. Leonardi, P. M., Huysman, M., \& Steinfield, C. (2013). Enterprise Social Media: Definition, History, and Prospects for the Study of Social Technologies in Organizations. Journal of Computer-Mediated Communication, 19(1), 1-19.

32. Lovejoy, K., \& Saxton, G. D. (2012). Information, Community, and Action: How Non-profit Organizations Use Social Media?. Journal of Computer-Mediated Communication, 17(3), 337-353.

33. Lovejoy, K., Waters, R. D., \& Saxton, G. D. (2012). Engaging stakeholders through Twitter: How non-profit organizations are getting more out of 140 characters or less. Public Relations Review, 38(2), 313-318.

34. Macnamara, J., \& Zerfass, A. (2012). Social media communication in organizations: The challenges of balancing openness, strategy, and management. International Journal of Strategic Communication, 6(4), 287-308.

35. Mergel, I., \& Bretschneider, S. I. (2013). A three-stage adoption process for social media use in government. Public Administration Review, 73(3), 390-400.

36. Nabukenya, J., Van Bommel, P., Proper, H. A., \& De Vreede, G. J. (2011). An evaluation instrument for collaborative processes: application to organizational policy-making. Group Decision and Negotiation, 20(4), 465-488.

37. O'Connor, K. W., Schmidt, G. B., \& Drouin, M. (2016). Helping workers understand and follow social media policies. Business Horizons, 59, 205-211.

38. Parasnis, G. (2011). From Social Media to Social Customer Relationship Management. Strategy \& Leadership, 39(5), 30-37.

39. Prus, R. (2003). Policy as a collective venture: a symbolic interactionist approach to the study of organizational directives. International Journal of Sociology and Social Policy, 23(6/7), 13-60.

40. Quinn, R. E., Hildebrandt, H. W., Rogers, P. S., \& Thompson, M. P. (1991). A Competing Values Framework for Analyzing Presentational Communication in Management Contexts. Journal of Business Communication, 28(3), 213-232.

41. Saxton, G. D., \& Waters, R. D. (2014). What do Stakeholders Like on Facebook? Examining Public Reactions to Non-profit Organizations' Informational, Promotional, and Community-Building Messages. Journal of Public Relations Research, 26(3), 280-299.

42. Six, F., \& Sorge, A. (2008). Creating a High-Trust Organization: An Exploration into Organizational Policies that Stimulate Interpersonal Trust Building. Journal of Management Studies, 45(5), 857884.

43. Stevens, B. (1994). An analysis of corporate ethical code studies: "Where do we go from here?". Journal of Business Ethics, 13(1), 63-69.

44. Stevens, B. (1996). Using the Competing Values Framework to Assess Corporate Ethical Codes. Journal of Business Communication, 33(1), 71-84.

45. Tyler, T. R., \& Blader, S. L. (2005). Can businesses effectively regulate employee conduct? The antecedents of rule following in work settings. Academy of Management Journal, 48(6), 1143-1158.

46. Vaast, E., \& Kaganer, E. (2013). Social media affordances and governance in the workplace: An examination of organizational policies. Journal of Computer-Mediated Communication, 19(1), 78-101.

47. Waters, R. D., Burnett, E., Lamm, A., \& Lucas, J. (2009). Engaging stakeholders through social networking: How non-profit organizations are using Facebook. Public Relations Review, 35(2), 102106.

\footnotetext{
${ }^{1}$ This does not imply that other companies or organizations have not developed their own social media policies, but rather that they were not publically available to the researchers during the course of this study. Additionally, some policies were omitted from analysis as they were used in the coder training process.
} 